\title{
Effect of Amphotericin B on the Permeability of the Toad Bladder*
}

\author{
Norman S. Lichtenstein and Alexander Leaf $†$ \\ (From the Departments of Medicine, Harvard Medical School and the Massachusetts General \\ Hospital, Boston, Mass.)
}

Neurohypophyseal hormones have been found to induce large net transfers of water across various transporting epithelia from anurans while the low permeability of these tissues to small solute molecules is retained. Since the water is considered to move in bulk through aqueous channels in such circumstances $(1,2)$, an explanation has been needed to account for the concomitant low permeability of these channels to small hydrophilic solutes. Andersen and Ussing (3) postulated the existence of a double series permeability barrier to account for this discrepancy in toad skin, and this concept has been extended to the toad bladder (4). A homogeneous outer diffusion barrier, highly permeable to water but of low permeability to most hydrophilic solutes, is considered to overlie a deeper porous barrier in which the porosity is increased by neurohypophyseal hormones. Since water crosses the diffusion barrier readily, changes in the porous layer will determine the characteristics of net water transport. The penetration of the bladder by small solute molecules, effectively blocked at the outer diffusion barrier, is unaffected by hormonally induced changes in the porous layer.

It became apparent that these considerations could not be restricted to water alone, on the one hand, and to all solutes, on the other, because the permeability of the toad bladder to urea and a small group of related, uncharged amides was found to be markedly enhanced by neurohypophyseal hormones $(4,5)$. These hormones also specifically stimulate the active transport of sodium

* Submitted for publication February 1, 1965 ; accepted April 22, 1965.

Supported by grants from the John A. Hartford Foundation, Inc., and U. S. Public Health Service grants HE-06664 and AM-04501.

Presented in part at the Biophysical Society Meetings in San Francisco, February 24-26, 1965.

$\dagger$ Address requests for reprints to Dr. Alexander Leaf, Massachusetts General Hospital, Boston, Mass. 02114. in the tissues considered $(6,7)$. In order to preserve a unitary hypothesis for the action of neurohypophyseal hormones on the permeability characteristics of the toad bladder it was assumed that urea, its congeners, and sodium ions-like watersomehow penetrated the diffusion barrier readily so that their rate of penetration was determined by the porous barrier.

This unitary hypothesis of the hormonal action quickly encountered difficulties with respect to sodium transport: 1) Removal of potassium from the medium bathing the serosal surface of the toad bladder blocked the entry of sodium through the mucosal surface of this tissue with resultant failure of stimulation of sodium transport by vasopressin; however, little, if any, decrease in the hormonally induced enhancement of water transport was observed in these circumstances (8). 2) Sodium ions have been shown to interact specifically with some membrane component near the mucosal surface of the toad bladder $(9,10)$, whereas urea and water show no evidence for such interaction (4, $5)$. This interaction would have to occur in the dense diffusion barrier and seems the most likely place that vasopressin might enhance sodium transport. 3) Petersen and Edelman (11) have dissociated the effects of low concentrations of vasopressin in the presence of calcium on the permeability of the toad bladder to water and to sodium. 4) Morel (12) has found that various synthetic analogs of vasopressin affect the permeability of the frog bladder to sodium and to water to different degrees. These arguments require a separate locus of action of neurohypophyseal hormones on the permeability of the bladder to sodium and to water.

Although a double series barrier seemed a formal requirement to account for the permeability characteristics of the toad bladder and related transporting epithelia, some independent means 
for testing the existence of such a double barrier was required. A series of compounds that would react with known components of the cell membrane was tested. Amphotericin B, a substance thought to interact with the sterols of the cell membranes of microorganisms $(13,14)$ gave the most promising results. The purpose of the present study is to examine the effects of amphotericin $\mathrm{B}$ on the permeability characteristics of the toad bladder. It is concluded that this compound functionally removes the outer selective diffusion barrier leaving the deeper porous barrier relatively intact. This effect supports the dual barrier hypothesis and affords a means of examining the contribution made by each barrier separately to the permeability characteristics of the tissue.

\section{Methods}

Studies were made with the urinary bladder of the toad, Bufo marinus, according to the technique of Ussing and Zerahn (6). A double chamber was used (15) with one half bladder mounted across the two chambers, one quarter being used as the test preparation and the other quarter as either the control or as a second experiment. The cross-sectional area of each half chamber was 4.65 $\mathrm{cm}^{2}$. The short circuit current was measured and recorded automatically (16). For the water movement studies a chamber was designed which is similar to that recently described by Edelman, Petersen, and Gulyassy (17) but which permits the simultaneous measurement of both net water flow and short circuit current. As i1lustrated in Figure 1, the bladder is held firmly in place by a nylon mesh support at both surfaces. Thus, by preventing bladder movement, net transfer of water across the tissue can be easily and accurately measured. The cross-sectional area of the chamber is $7.07 \mathrm{~cm}^{2}$. For most of the experiments a sodium Ringer's solution was used that contained sodium chloride $114 \mathrm{mM}$, potassium chloride $3.5 \mathrm{mM}$, sodium bicarbonate $2.8 \mathrm{mM}$, and calcium chloride $0.89 \mathrm{mM}$. The $\mathrm{pH}$ was 7.8 and the osmolality $220 \mathrm{mOsm}$ per $\mathrm{kg}$ water. In the experiments measuring net flow of water, the solutions used were ordinary sodium Ringer's solution on the serosal side and sodium Ringer's solution diluted to produce the desired transepithelial osmotic gradient on the mucosal side.

Amphotericin B 1 was used as the water soluble preparation. Each vial contains $50 \mathrm{mg}$ lyophilized amphotericin $\mathrm{B}$ powder, $41 \mathrm{mg}$ sodium deoxycholate, $10 \mathrm{mg}$ disodium phosphate, $0.89 \mathrm{mg}$ monosodium phosphate, and $6.2 \mathrm{mg}$ sodium chloride. The solution was stored at $4^{\circ} \mathrm{C}$ in a dark container to prevent inactivation. The sodium deoxycholate is present in order to solubilize the amphotericin B. When the sodium deoxycholate was used alone, in the same concentrations as would ordinarily

\footnotetext{
${ }_{1}$ E. R. Squibb \& Sons, New Brunswick, N. J.
}

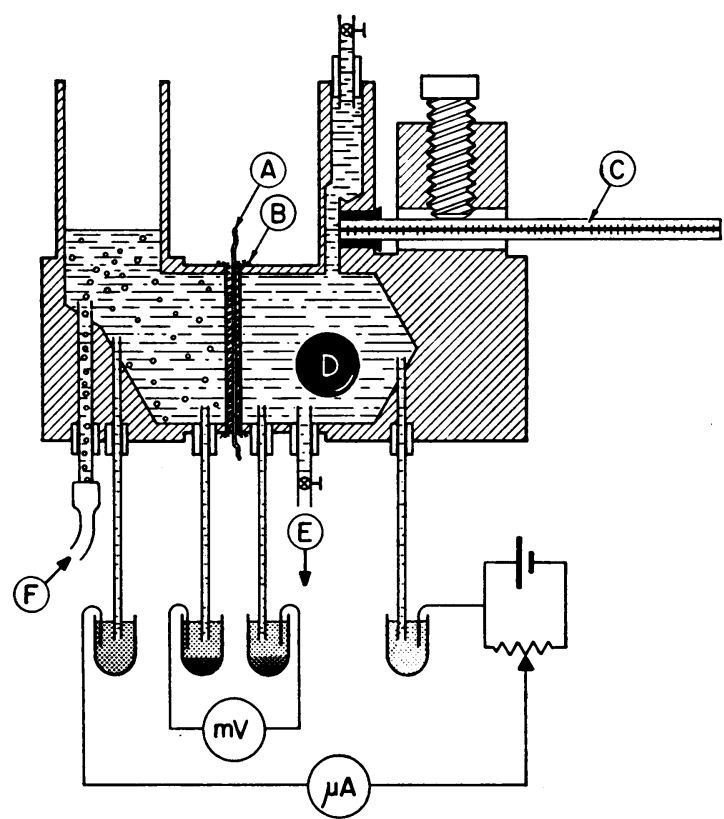

Fig. 1. Chamber USED to MEasure SHORT CIRCUIt CURRENT AND NET WATER MOVEMENT SIMULTANEOUSLY. A refers to the toad bladder held firmly in place between the two halves of the Lucite chamber, each of which is covered by $B$, a nylon mesh support. $C$ is the calibrated pipette to measure net movement of water. D represents a steel ball in the chamber, which is acted upon by an external rotating magnet, not shown in the diagram, to stir the solution in the closed half chamber. $E$ is the outlet for the mucosal bathing medium. $F$ is connected by rubber tubing to an air outlet, which serves both to aerate and to stir the serosal bathing medium. The electrical short circuit diagram is also illustrated.

be present in the amphotericin B solution, no effects on the permeability of the tissue were observed. Furthermore, nystatin, a polyene antibiotic that produces changes in the permeability of the toad bladder similar to those seen with amphotericin $\mathrm{B}$, contains no deoxycholate in the preparation used. The changes reported, therefore, may be ascribed to the action of amphotericin $B$ alone on the tissue.

Isotopes used were tritiated water (THO), urea-C ${ }^{14}$, thiourea-C ${ }^{14}$, methylurea- $C^{14}$, and butyramide- $C^{14} ;{ }^{2} \mathrm{Na}^{24}$ and $\mathrm{K}^{22} ;{ }^{3}$ and $\mathrm{Na}^{22}$ and $\mathrm{Cl}^{36} .4 \quad \mathrm{Na}^{24}$ and $\mathrm{K}^{22}$ were counted with an auto-gamma spectrometer ${ }^{5}$ and the urea- $\mathrm{C}^{\mathbf{1 4}}$, thiourea- $\mathrm{C}^{14}, \mathrm{Cl}^{36}$, and THO with a Tri-Carb liquid scintillation spectrometer ${ }^{5}$ using a naphthalene-dioxane solution (18). The permeability coefficients were calculated by adding the isotope to the medium bathing one side and measuring its rate of appearance on the other side (5).

\footnotetext{
2 New England Nuclear Corp., Boston, Mass.

3 Iso/Serve Co., Boston, Mass.

4 Nuclear Science and Engineering Corp., Pittsburgh, $\mathrm{Pa}$.

5 Packard Instruments Cu., La Grange, Ill.
} 


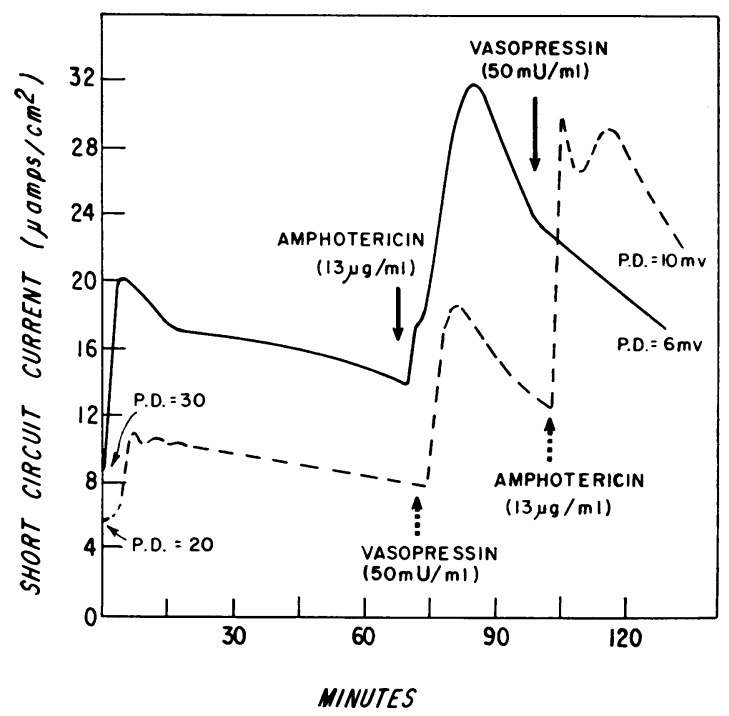

Fig. 2. EFfect of AMpHotericin B AND VASOPRESSIN ON THE SHORT CIRCUIT CURRENT ACROSS THE TOAD BLADDER. With amphotericin $\mathrm{B}$ added to the mucosal bathing medium, a large stimulation of short circuit current occurred that was not further augmented by vasopressin. Initial addition of vasopressin caused a smaller rise in short circuit current followed by a large increase upon addition of amphotericin $\mathrm{B}$. These changes were accompanied by a decrease in the electrical resistance, as can be seen from the initial and final potential differences (P.D.) across each quarter bladder.

Measurements of oxygen consumption were made using conventional manometric techniques (19). All solutions were bicarbonate-free and were buffered with phosphate or Tris. In the sodium-free Ringer's solution the sodium was replaced by either choline or magnesium. The final concentrations of sodium were determined by flame photometry, using a Baird-Atomic flame photometer. ${ }^{6}$

\section{Results}

Effect on sodium transport. Figure 2 shows a typical result of the addition of amphotericin B to the medium bathing the mucosal surface of the toad bladder. Within 30 seconds one observes the onset of a large rise in short circuit current, a relatively smaller rise in potential, and a drop in resistance. The magnitude and duration of the response is dependent upon the concentration used. A low concentration of $2 \mu \mathrm{g}$ per ml produces only a slight rise in short circuit current; a high concentration of $13 \mu \mathrm{g}$ per $\mathrm{ml}$ produces a maximal rise, usually two to five times greater than the control

\footnotetext{
6 Baird Associates, Cambridge, Mass.
}

value. After the maximal effect has been produced there is a steady decline in short circuit current, potential difference, and resistance, reaching low levels after 2 hours. These effects cannot be reversed by removing the amphotericin $B$ from the bathing solution.

The response to amphotericin B occurs only if it is added to the mucosal medium. Amounts even three times the maximum can be added to the serosal medium, and over the ensuing 3 hours no detectable effect on the short circuit current is observed.

After a maximal response of the short circuit current to amphotericin B has been produced, addition of vasopressin results in no further stimulation. This is again shown in Figure 2, which is representative of approximately 40 similar experiments in which the final amphotericin B concentration was $13 \mu \mathrm{g}$ per $\mathrm{ml}$. At no time was a further increase in short circuit current observed after the maximal amphotericin B response had been produced. With concentrations of amphotericin B less than $10 \mu \mathrm{g}$ per ml, however, a slight further increase in short circuit current may occur upon the addition of vasopressin.

Figure 2 also demonstrates the effect of reversing the order of addition of amphotericin B and vasopressin. If vasopressin is given first, there is the usual increase in short circuit current; subsequent addition of amphotericin B, however, always yields a further increase over that induced by vasopressin alone.

Since the effect of amphotericin B is to produce marked changes in permeability, it was thought essential to determine whether the measured short circuit current was still equal to the net sodium flux. In eight experiments using the double labeling technique of Ussing and Zerahn (6), the net sodium flux and the short circuit current were identical in the control periods, as shown in Table I. In the first half hour after the addition of amphotericin B (14 $\mu \mathrm{g}$ per $\mathrm{ml})$ the net sodium flux and the short circuit current both increased nearly proportionately. In the second half hour, however, although the net sodium flux increased threefold over the control period, the short circuit current only doubled. The lesser rise of the short circuit current than of the mean sodium flux probably reflects leakage of ions from the cells, most likely potassium. 
TABLE I

Comparison of the net sodium flux and the short circuit current across the toad bladder before and after amphotericin $B^{*}$

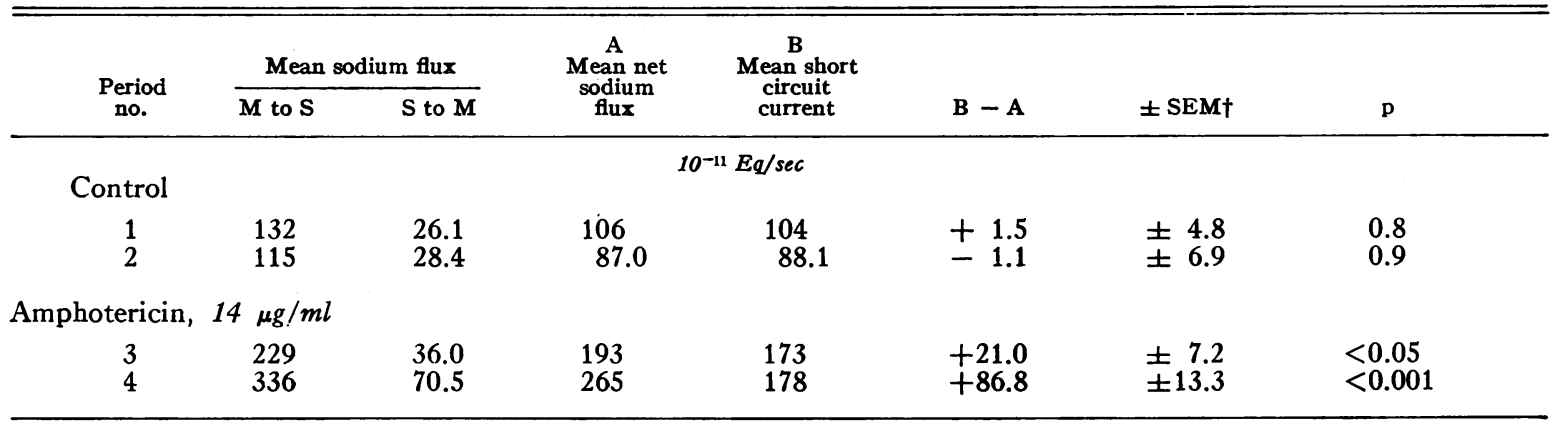

* Sodium flux was measured from mucosal to serosal surfaces ( $M$ to $S$ ) by means of $\mathrm{Na}^{22}$ and simultaneously in the opposite direction ( $\mathrm{S}$ to $\mathrm{M}$ ) with $\mathrm{Na}^{24}$. The short circuit current was determined simultaneously and recorded automatically. The results from a total of eight experiments are presented; in each experiment each period was one-half hour in length. The amphotericin B was added at the end of period 2. Note the good agreement between mean net sodium flux and mean short circuit current in the two control periods. After the addition of amphotericin B, however, there is a lesser rise in mean short circuit current than in the mean net sodium flux, indicative of some asymmetric leak of ions from the cells.

$\dagger \mathrm{SEM}=$ standard error of the mean.

Effect on permeability to potassium, chloride, and thiourea. The effect of amphotericin $\mathrm{B}$ on the permeability of the bladder to substances that are not actively transported across the tissue, namely, potassium, chloride, and thiourea, was tested. For potassium and thiourea the permeability was measured from the mucosal to serosal surface; for chloride, measurements in separate bladders in both directions were done, and the results were essentially the same. Previous data have shown that the permeability of the bladder to these substances is unaffected by vasopressin (4). The addition of amphotericin B, as shown in Table II, results in a large increase in the permeability of the bladder to these compounds.

Effect on net movement of water. Although amphotericin $\mathrm{B}$ was able to increase the perme-

TABLE II

Effect of amphotericin $B$ on the permeability of the toad bladder to potassium, chloride, and thiourea*

\begin{tabular}{lcrccc}
\hline \hline & $\begin{array}{c}\text { No. of } \\
\text { experi- } \\
\text { ments }\end{array}$ & Control & $\begin{array}{c}\text { Ampho- } \\
\text { tericin B }\end{array}$ & $\Delta \pm \mathrm{SEM}$ & $\mathrm{p}$ \\
\hline & & & $K_{\text {trane in } 10^{-7} \mathrm{~cm} / \mathrm{sec}}$ & \\
Potassium & 6 & 3.8 & 57.2 & $53.3 \pm 10.9$ & $<0.01$ \\
Thiourea & 5 & 10.6 & 92.7 & $82.1 \pm 11.5$ & $<0.01$ \\
Chloride & 7 & 5.3 & 16.2 & $10.9 \pm 2.8$ & $<0.01$
\end{tabular}

* In each experiment following 15 minutes of equilibration for the isotope the permeability across the tissue was determined for one or two 30-minute control periods. Amphotericin B (13 $\mu \mathrm{g}$ per $\mathrm{ml}$ ) was then added to the mucosal medium, and a further two or three 30-minute periods were obtained. The mean values of control and experimental periods, respectively, are recorded. $K_{\text {trans }}=$ permeability coefficient . ability to a wide variety of substances such as sodium, potassium, chloride, and thiourea, it specifically failed to increase the net movement of water; vasopressin still exerted its usual effect upon that parameter.

Table III shows the results of amphotericin B and vasopressin upon net movement of water. In these experiments an osmotic gradient was established across the bladder by using as the mucosal bathing medium sodium Ringer's solution diluted to one-fifth of its normal tonicity. A control period of 20 to 40 minutes was followed by the addition of amphotericin $\mathrm{B}$ in concentrations ranging between 4 and $22 \mu \mathrm{g}$ per ml. Over the next 20 to 40 minutes, there was then a slight, but not statistically significant, increase in net movement of water. Subsequently, the addition of vasopressin to the serosal solution resulted in the expected large net movement of water. In each of the experiments the addition of amphotericin B caused a marked increase in short circuit current, but no further increase was observed upon addition of the vasopressin.

Series 2 in Table III represents another group of eight experiments similar to those already described except that as a final step the serosal solution was replaced with fresh Ringer's solution in order to remove the vasopressin. The purpose here was to determine whether the usual reversal of the vasopressin effect could still be observed after exposure of the tissue to amphotericin B. Col- 
TABLE III

Effect of amphotericin $B$ and vasopressin on net transfer of water across the toad bladder*

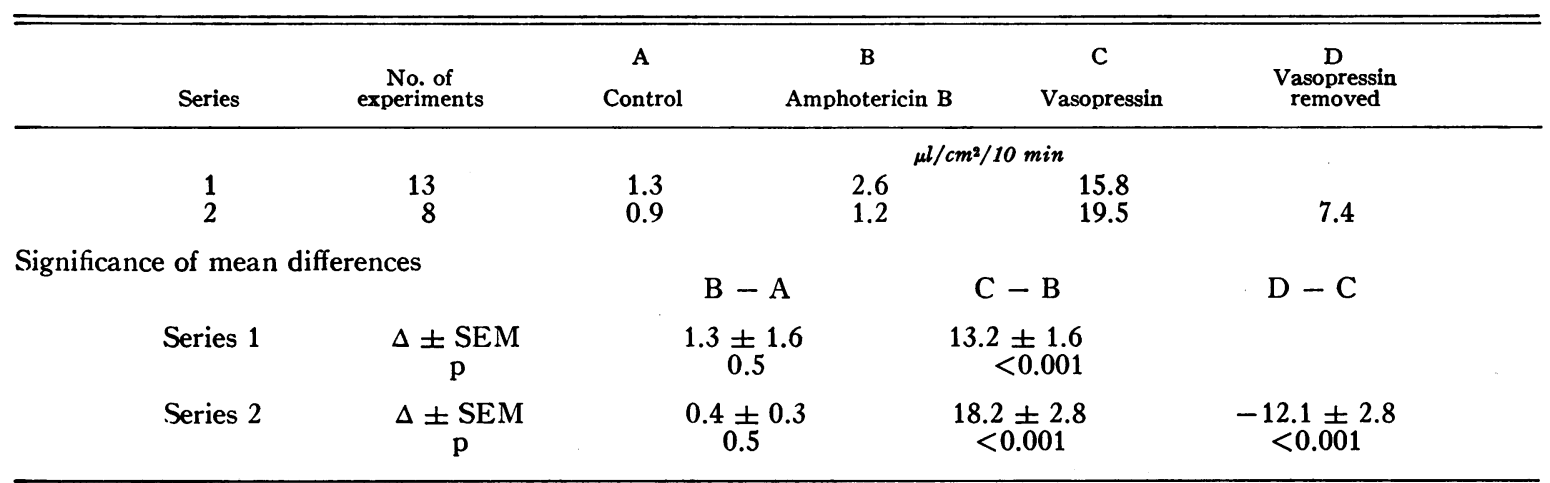

* The osmotic gradient was established with sodium Ringer's solution as the serosal bathing medium and sodium Ringer's solution (diluted $1: 4$ ), as the mucosal bathing medium. Concentrations of amphotericin $B$ were between 4 and $22 \mu \mathrm{g}$ per $\mathrm{ml}$. Periods A through D each varied from 20 to 40 minutes in length.

umn D of Table III indicates that the vasopressin effect on net water movement was partially reversible.

Figure 3 shows one illustrative example of these eight experiments. Amphotericin B pro- duced a large rise in short circuit current, a small rise in potential difference, but no effect upon net water movement. Vasopressin caused essentially no increase in the short circuit current or potential difference but did induce a large net movement of

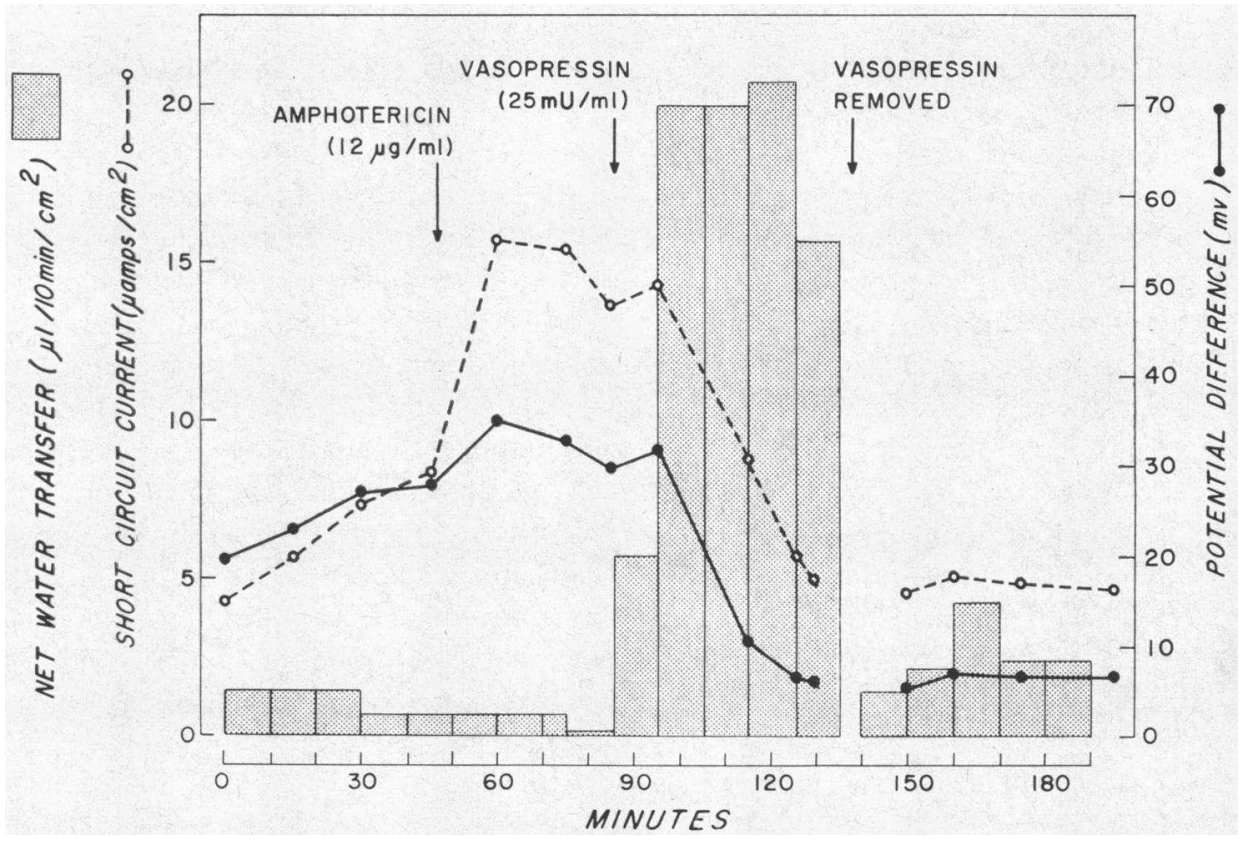

Fig. 3. COMPARISON OF THE EFFECTS OF AMPHOTERICIN B AND VASOPRESSIN ON SHORT CIRCUIT CURRENT, POTENTIAL DIFFERENCE, AND NET WATER MOVEMENT ACROSS THE TOAD BLADDER. Addition of amphotericin $B$ to the mucosal medium produced a large increase in short circuit current without affecting net movement of water. Subsequent addition of vasopressin failed to augment the short circuit current, but produced its usual large effect on transport of water. When vasopressin was removed, the net transport of water was reduced. In this experiment sodium Ringer's solution was used as the serosal bathing medium and sodium Ringer's solution (diluted $1: 4$ ) as the mucosal bathing medium. 
water. The decline in short circuit current and potential difference is the usual pattern seen after 30 to 60 minutes of amphotericin B. Finally, removing vasopressin from the serosal solution returned the bladder to a state of relative impermeability to water once again.

Effect on the diffusion of water. The effect of amphotericin B on the diffusion of water in the absence of an osmotic gradient was also studied. The unidirectional flux of water was measured with tritiated water. The permeability coefficient, $\mathrm{K}_{\text {trans }}$, for labeled water was determined as described previously (20). The total duration of each experiment was 1 hour and consisted of a 20minute control period, an amphotericin $\mathrm{B}$ period of 20 minutes, and a final 20-minute period with vasopressin.

Table IV shows that in fourteen experiments amphotericin B produced a highly significant increase in the rate of penetration of the tissue by labeled water. Subsequent exposure to vasopressin yielded an additional increment in permeability to water in the third period. Series 1 of Table IV also indicates that in eight control experiments in which no vasopressin was added after the amphotericin B, no significant further increase in permeability to water was observed in period $\mathrm{C}$.

Effect on permeability to urea. The results of amphotericin $\mathrm{B}$ upon the permeability of the toad bladder to urea are shown in Table V. In each of the seven experiments in series 1 there were two 20-minute control periods, three 20-minute periods following the addition of amphotericin $\mathrm{B}$, and three further 20-minute periods after the addition of vasopressin. In series 2 the order of addition of amphotericin B and vasopressin was reversed. The results show that vasopressin caused a sevenfold increase in the permeability to urea, and subsequent addition of amphotericin $\mathrm{B}$ had no further effect. Amphotericin B given first produced a fivefold increase in permeability, and vasopressin caused no additional increase.

The absolute magnitude of the increase varied slightly depending upon whether amphotericin B or vasopressin was added first, but the pertinent finding is that the subsequent addition of the other agent was without further effect. The implication from these experiments is that both vasopressin and amphotericin $\mathrm{B}$ affect the same barrier for urea. To determine whether the other urea analogs (4) were similarly affected $N$-methyl urea$\mathrm{C}^{14}$ and butyramide- $\mathrm{C}^{14}$ were tested. In one pair of experiments with each, addition of either amphotericin B or vasopressin enhanced permeability, but there was no further increase after the subsequent addition of the other agent; the results, therefore, were similar to those with urea.

Effect on permeability to urea and net move-

TABLE IV

Effect of amphotericin $B$ and vasopressin on the diffusion of water across the toad bladder*

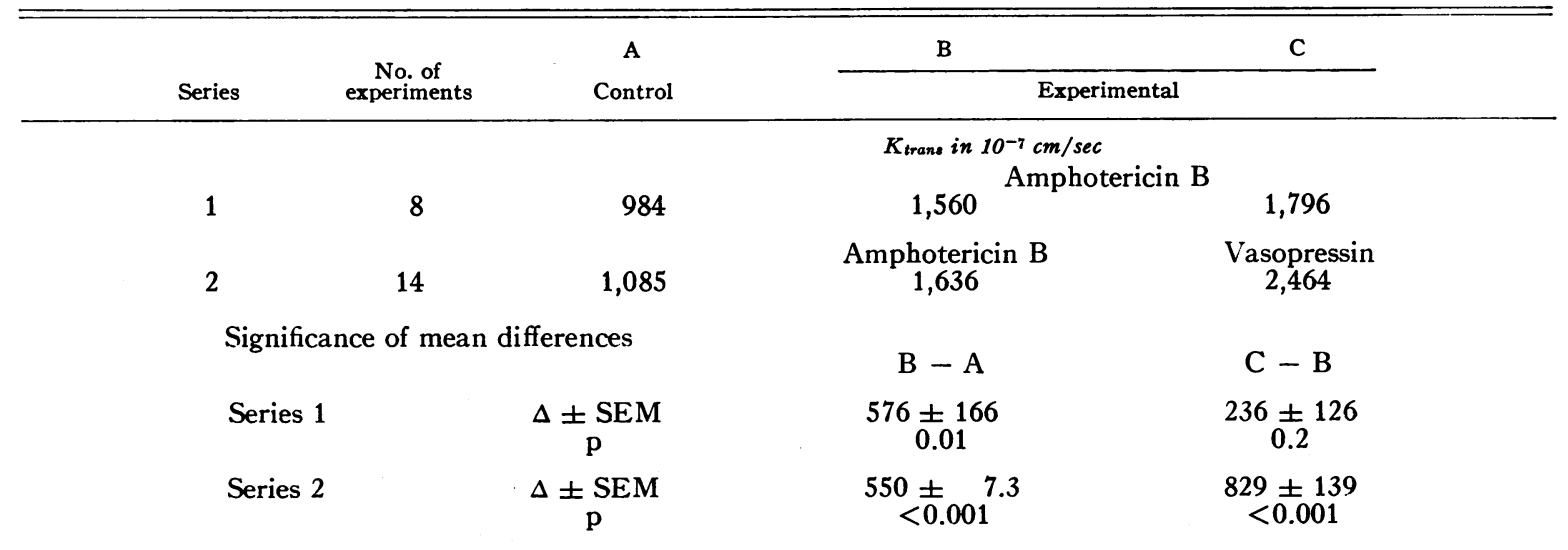

* In each experiment the isotopically labeled water (THO) was added to the mucosal bathing medium. After 20 minutes of equilibration the flux of isotope through the tissue was determined for one 20-minute control period. In series 1 amphotericin $B(13 \mu \mathrm{g}$ per $\mathrm{ml}$ ) was then added to the mucosal medium, and observations were made for two additional 20-minute periods. In series 2 after one 20 -minute period with amphotericin $\mathrm{B}$, vasopressin $(50 \mathrm{mU}$ per $\mathrm{ml})$ was added to the serosal bathing medium and a final 20 -minute period obtained. The mean values of control, amphotericin $B$, and vasopressin periods, respectively, are recorded. 
TABLE V

Effect of amphotericin $B$ and vasopressin on the permeability of the toad bladder to urea*

\begin{tabular}{|c|c|c|c|c|}
\hline \multirow[b]{2}{*}{ Series } & \multirow{2}{*}{$\begin{array}{c}\text { No. of } \\
\text { experiments }\end{array}$} & \multirow{2}{*}{$\begin{array}{c}\text { A } \\
\text { Control }\end{array}$} & B & C \\
\hline & & & \multicolumn{2}{|c|}{ Experimental } \\
\hline & & & \multicolumn{2}{|c|}{$K_{\text {trans }}$ in $10^{-7} \mathrm{~cm} / \mathrm{sec}$} \\
\hline 1 & 7 & 30.1 & $\begin{array}{c}\text { Amphotericin B } \\
139\end{array}$ & $\begin{array}{c}\text { Vasopressin } \\
158\end{array}$ \\
\hline 2 & 6 & 29.7 & $\begin{array}{c}\text { Vasopressin } \\
214\end{array}$ & $\begin{array}{c}\text { Amphotericin B } \\
226\end{array}$ \\
\hline \multicolumn{3}{|c|}{ Significance of mean differences } & $\mathrm{B}-\mathrm{A}$ & $\mathrm{C}-\mathrm{B}$ \\
\hline & & $\Delta \pm \underset{\mathbf{p}}{\mathrm{SEM}}$ & $\begin{array}{c}109 \pm 22.6 \\
<0.001\end{array}$ & $\begin{array}{c}18.7 \pm 14.6 \\
0.3\end{array}$ \\
\hline & & $\Delta \pm \underset{p}{\operatorname{SEM}}$ & $\begin{array}{c}185 \pm 38.8 \\
<0.01\end{array}$ & $\begin{array}{c}11.3 \pm 11.3 \\
0.5\end{array}$ \\
\hline
\end{tabular}

* In each experiment the isotope was added to the mucosal bathing medium. After 20 minutes of equilibration the flux of isotope through the tissue was determined for two 20-minute control periods. In series 1 amphotericin B (13 $\mu \mathrm{g}$ per $\mathrm{ml}$ ) was then added to the mucosal medium, and three 20-minute periods were measured; vasopressin (50 mU per ml) was subsequently added to the serosal bathing medium, and three additional 20 -minute periods were obtained. In'series 2 the order of amphotericin B and vasopressin was reversed. The mean values of control, amphotericin B, and vasopressin periods, respectively, are recorded.

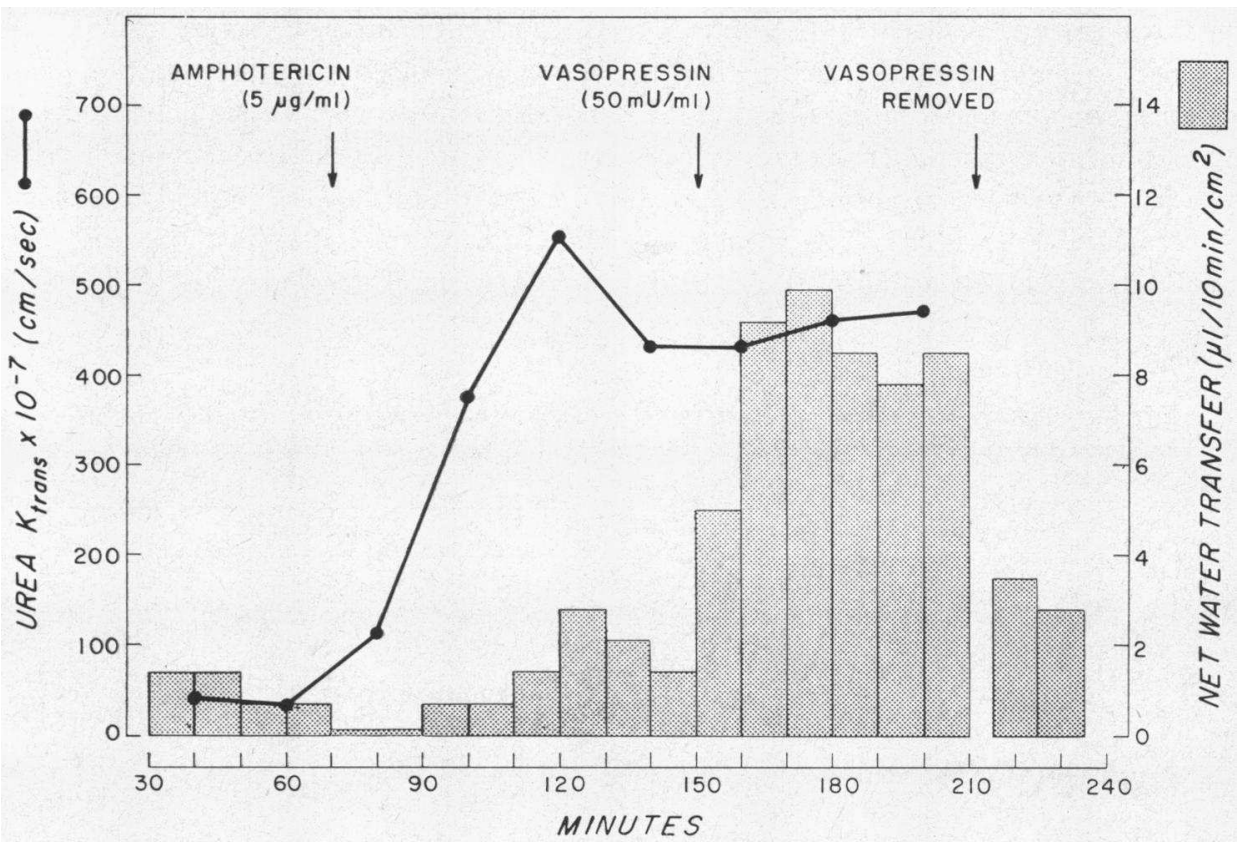

Fig. 4. EFFECT OF AMPhOtericin B AND VASOPRESSIN ON NET WATER TRANSFER AND PERMEABILITY To UREA. Amphotericin $B$ added to the mucosal bathing medium produced a large increase in the permeability of the bladder to urea and a slight increase in net water movement. Subsequently vasopressin had no further effect on the tissue permeability to urea but did cause the usual large increase in net water transfer. Removal of vasopressin reduced net water transfer to lower levels. In this experiment the initial short circuit current was $56 \mu \mathrm{a}$, the potential difference was $6 \mathrm{mv}$; the final values were $58 \mu \mathrm{a}$ and $6 \mathrm{mv}$, respectively. Sodium Ringer's solution (diluted $1: 1$ ) on the mucosal side provided the osmotic gradient. $\mathrm{K}_{\mathrm{trans}}=$ permeability coefficient. 
ment of water measured simultaneously. The results in Tables III and V indicate that after amphotericin B vasopressin exerts no further effect on urea but still has its usual effect on net movement of water. This was tested directly with measurements made simultaneously on permeability to urea and on net water flow in the same half bladders. Figure 4 is a typical result, representative of eight similar experiments. Amphotericin B in a concentration of $5 \mu \mathrm{g}$ per $\mathrm{ml}$ caused a large increase in permeability to urea but only a slight net movement of water. The addition of vasopressin 1 hour later produced no further effect on the permeability to urea but caused the expected large net movement of water. Removal of vasopressin from the serosal solution restored the relative impermeability to water.

Table VI shows the results of the eight experiments in which the permeability coefficient for urea, $\mathrm{K}_{\text {trans }}$, and the osmotic flow of water were measured simultaneously in the same half bladders. The results are in agreement with the urea and osmotic water flow experiments done separately (Tables III and V), namely, that amphotericin B alone produces a large increase in the permeability to urea, whereas vasopressin causes no further increase but at the same time induces a large net movement of water. Also it is apparent that af- ter exposure for more than 2 hours to $5 \mu \mathrm{g}$ per $\mathrm{ml}$ amphotericin B the removal of vasopressin restored the bladders to a state of relative impermeability to water.

In these experiments the concentration of amphotericin B used was $5 \mu \mathrm{g}$ per $\mathrm{ml}$. Although this is less than the amount necessary to induce a maximal effect on sodium transport that is not further increased by vasopressin, it is sufficient to produce a maximal response on the permeability to urea that is not further enhanced by vasopressin. Thus there is a different dose-response relationship with amphotericin B for a maximal effect on the permeability of the bladder to urea and to sodium.

Effect of mucosal acidification. In the toad bladder lowering of the mucosal $\mathrm{pH}$ stimulates the short circuit current (21). However, Figure 5, representative of four similar experiments, demonstrates that addition of acid to a bladder already exposed to amphotericin B fails to produce an increase but rather causes a depression in the short circuit current.

Effect of absent serosal potassium. In the toad bladder absence of potassium from the serosal bathing medium effectively abolishes sodium transport (8). It is thought that the major cause of this effect is a reduction in the permeability of the mucosal surface to sodium (22). Since ampho-

TABLE VI

Effect of amphotericin $B$ and vasopressin in the toad bladder on the permeability to urea and on net water movement measured simultaneously*

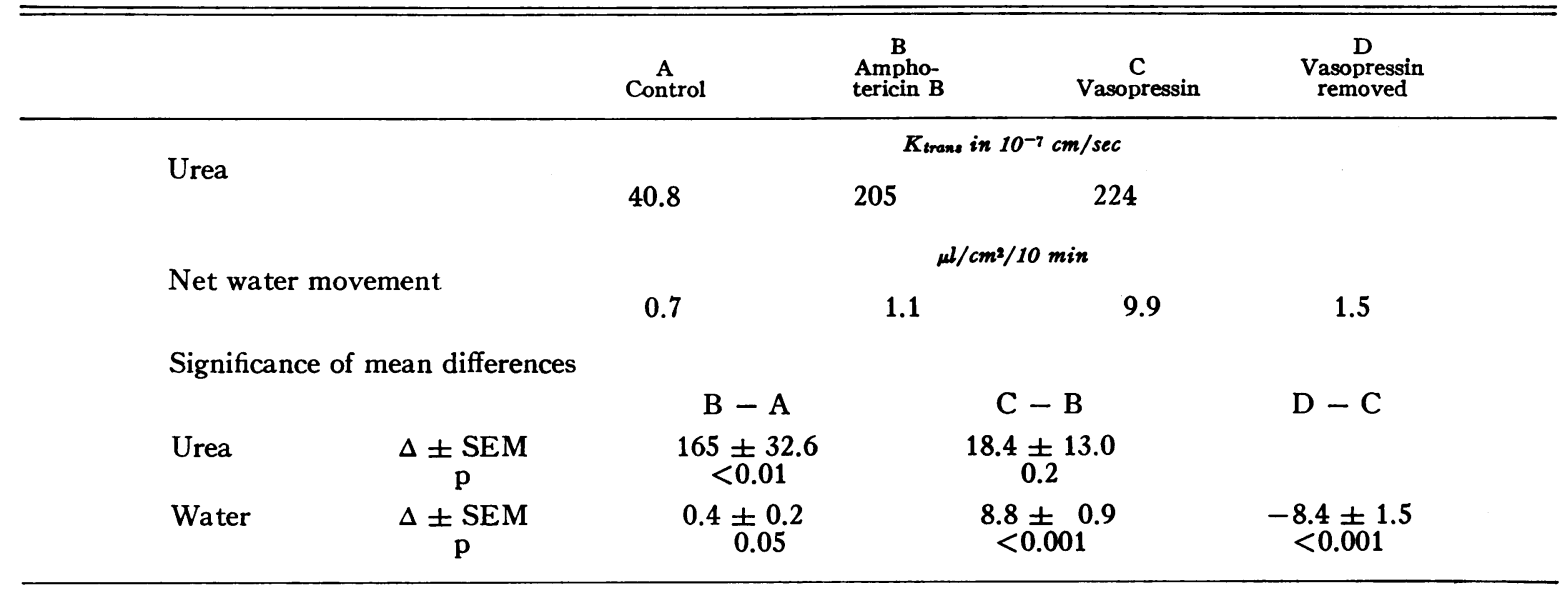

* The results are the means of measurements in eight experiments in which the permeability to urea and net water transport were determined simultaneously. The osmotic gradient was established with sodium Ringer's solution as the serosal bathing medium and sodium Ringer's solution (diluted 1:1) as the mucosal bathing medium. The final amphotericin $\mathrm{B}$ concentration was $5 \mu \mathrm{g}$ per $\mathrm{ml}$. The duration and sequence of the periods were the same as in series 1 of Table V. 


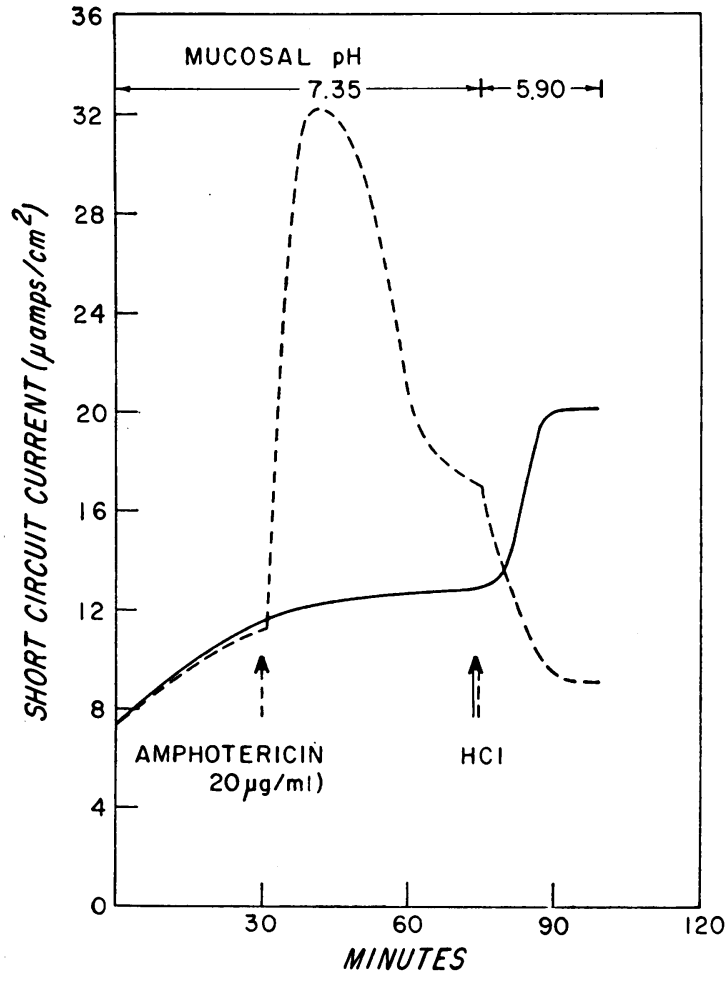

Fig. 5. EFFECT OF AMPHOTERICIN B AND MUCOSAL ACIDIFICATION ON SHORT CIRCÜIS CURRENT. Addition of amphotericin B resulted in the customary large, but in this instance transient, rise in short circuit current. Acidification of the mucosal medium produced an abrupt drop in short circuit current, whereas the control exhibited the usual stimulatory effect. Phosphate Ringer's solution was used as the bathing medium in this experiment.

tericin B appears to increase the permeability of this surface, its effect on sodium transport in the absence of serosal potassium was examined. In four experiments, of which Figure 6 is representative, a potassium-free sodium Ringer's solution was used as the medium bathing both sides of the bladder. After a rapid decline in short circuit current, addition of amphotericin B caused a large stimulation. Subsequent replacement of potassium then resulted in a further increase in current.

Effect on oxygen consumption. In association with the increased active sodium transport caused by amphotericin B, a higher rate of oxygen consumption would also be expected. The oxygen consumption of paired bladder halves was measured using the conventional Warburg apparatus. In these experiments each flask contained two half bladders in $3 \mathrm{ml}$ sodium Ringer's solution.
After two control periods of 1 hour each, amphotericin B was tipped into one of the paired vessels from its sidearm to give a final concentration of $17 \mu \mathrm{g}$ per ml. As shown in Table VII, the result was to increase the oxygen consumption (microliters per milligram dry weight per hour) from 1.38 to 1.99 .

To establish that the increase in oxygen consumption following amphotericin B was in fact related to stimulation of sodium transport, an additional nine paired studies were performed in the absence of sodium. Sodium was replaced by choline in six and by magnesium in three paired experiments. A lower base-line oxygen consumption was observed compatible with the absence of sodium transport $(7,23)$. Upon addition of amphotericin $\mathrm{B}$ there was no further increase in oxygen consumption. The actual final concentrations of sodium measured by flame photometry were between 2.5 and $4.0 \mathrm{mEq}$ per $\mathrm{L}$ in eight pairs and $10 \mathrm{mEq}$ per $\mathrm{L}$ in one pair of experiments.

To verify that the effects on the permeability of the tissue could still be exerted by amphotericin B, even in the absence of sodium, experiments with

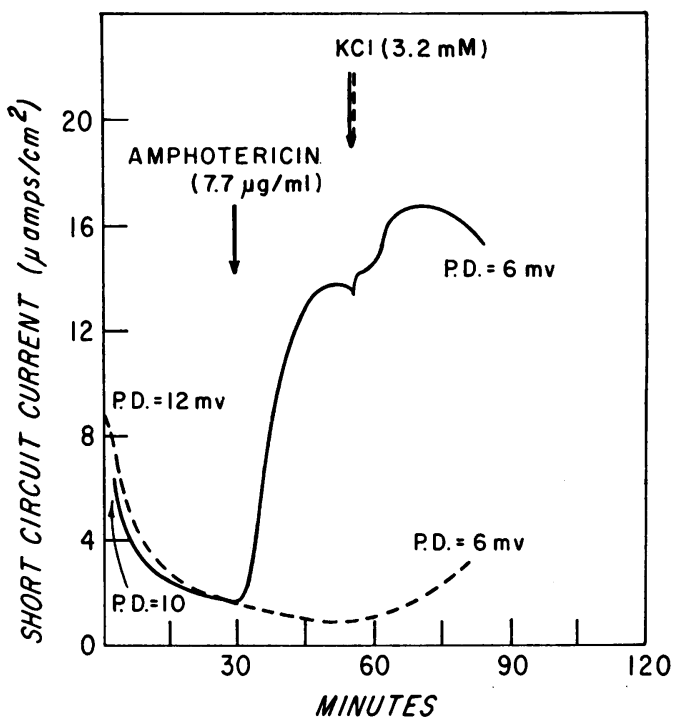

Fig. 6. EFFect of AMpHotericin B IN THE ABSENCE OF SEROSAL POTASSIUM. With no potassium in the serosal bathing medium the expected sharp decline in sodium transport was observed. Addition of amphotericin B resulted in a prompt, large stimulation of short circuit current that was further enhanced by potassium. In the control tissue potassium resulted in a slower rise in short circuit current. 
TABLE VII

Effect of amphotericin B on the oxygen consumption of the toad bladder*

\begin{tabular}{|c|c|c|c|c|c|c|}
\hline & \multicolumn{3}{|c|}{ Hours } & \multirow{2}{*}{$\begin{array}{c}\text { Mean } \\
\text { difference } \\
\text { (hours 3-2) }\end{array}$} & \multirow[b]{2}{*}{ SEM } & \multirow[b]{2}{*}{ p } \\
\hline & 1 & 2 & 3 & & & \\
\hline \multicolumn{7}{|c|}{ Sodium Ringer's ( 9 paired experiments) } \\
\hline $\begin{array}{l}\text { Control } \\
\text { Amphotericin B }\end{array}$ & $\begin{array}{l}1.43 \\
1.47\end{array}$ & $\begin{array}{l}1.33 \\
1.38\end{array}$ & $\begin{array}{l}1.25 \\
1.99\end{array}$ & $\begin{array}{l}-0.082 \\
+0.608\end{array}$ & $\begin{array}{l} \pm 0.026 \\
\pm 0.051\end{array}$ & $\begin{array}{l}<0.02 \\
<0.001\end{array}$ \\
\hline \multicolumn{7}{|c|}{ Sodium-free Ringer's ( 9 paired experiments) } \\
\hline $\begin{array}{l}\text { Control } \\
\text { Amphotericin B }\end{array}$ & $\begin{array}{l}0.97 \\
0.99\end{array}$ & $\begin{array}{l}0.90 \\
0.91\end{array}$ & $\begin{array}{l}0.93 \\
0.99\end{array}$ & $\begin{array}{l}+0.036 \\
+0.073\end{array}$ & $\begin{array}{l} \pm 0.042 \\
\pm 0.034\end{array}$ & $\begin{array}{l}<0.50 \\
<0.1\end{array}$ \\
\hline
\end{tabular}

* Measurements of oxygen consumption $\left(\mathrm{QO}_{2}=\right.$ microliters per milligram dry weight per hour) were made using conventional manometric techniques. All solutions were bicarbonate-free and were buffered with phosphate or Tris. In the sodium-free Ringer's solution the sodium was replaced by choline in six, and by magnesium in three, of the paired experiments. Amphotericin $\mathrm{B}$ in a final concentration of $\mathbf{1 7} \mu \mathrm{g}$ per $\mathrm{ml}$ was added after the second hour.

tracer amounts of sodium and urea were performed using choline Ringer's solution. The result was that amphotericin B induced large increases in the permeability of the bladder to these substances, similar to the effects seen in ordinary sodium Ringer's solution.

Effect of nystatin. To determine whether these effects on permeability were peculiar to amphotericin $B$ or shared by other polyene antibiotics, nystatin, a compound similar in structure to amphotericin B, was tested. The effects of nystatin on the short circuit current in six experiments, and on the permeability to urea in two experiments, were essentially the same as with amphotericin B. The effect upon the permeability to other substances was not tested.

Effects of digitonin. Saponins are known to form tight complexes with sterols. One such compound, digitonin, was tested to see whether its effects might parallel those of the polyene antibiotics, which are also thought to react chemically with sterols $(13,14)$. However, the results were variable and inconstant. In some sixteen experiments using digitonin in concentrations between 2 and 20 $\mu \mathrm{g}$ per $\mathrm{ml}$ there was, in five experiments, a stimulation but, in eleven experiments, a depression of the short circuit current.

\section{Discussion}

From kinetic studies of the permeability of the toad bladder, the concept had developed of a double series barrier located in or near the mucosal surface of the epithelial layer of cells. An outer dense diffusion barrier was considered to be the major obstacle to the penetration of this tissue by small solute molecules whereas water, which was thought to cross the diffusion barrier readily, was rate-limited by the porous barrier. Furthermore, the porous barrier was considered to be regulated by the neurohypophyseal hormones (4). Independent evidence for such a hypothesis has now been presented from these studies on the effects of amphotericin $\mathrm{B}$ on the permeability of the bladder.

Amphotericin B, added to the mucosal bathing medium, functionally removes the selective barrier to the penetration of the bladder by most small solute molecules. After addition of amphotericin $B$, thiourea, potassium, and chloride, which normally diffuse across the tissue at low rates because of a permeability restriction at the mucosal surface (4), show a prompt increase in their rates of penetration by some three- to fifteenfold. This evidence thus establishes a major site of action of amphotericin $B$ at the dense diffusion barrier in the mucosal surface of the epithelial layer of cells. But it is neither implied nor required for the present study that this be the sole site of action of the compound.

In accord with such a site of action is the fact that amphotericin B produces its effects solely when added to the mucosal bathing medium. When amphotericin $B$ is added to the serosal side no detectable changes in the permeability to water, urea, or sodium are observed. In spite of the striking changes in permeability, no gross morphological changes were detected by either light or electron microscopy in preliminary observations.

Having established that amphotericin B affects the dense diffusion but not the porous barrier, one can ascribe to each barrier its special role in deter- 
mining the permeability characteristics of this tissue. In particular the effect of amphotericin B has been examined on the permeability of the bladder to those substances-urea, water, and sodiumwhich are markedly affected by vasopressin.

In spite of functionally removing the dense diffusion barrier, addition of amphotericin B leaves the deeper porous barrier relatively intact. Bulk flow of water was not induced by amphotericin B but was still dependent upon the addition of vasopressin and could be largely reversed upon the removal of the hormone. Although the effects of amphotericin $\mathrm{B}$ on the permeability of the bladder to small solutes occurred immediately and were easily dissociated from any effect on bulk water movement, in experiments of long duration some late and gradual increase in net water transport was often encountered. This "leakiness" was more common after large doses of amphotericin B and in the presence of large osmotic gradients across the tissue.

Amphotericin B produced a definite increase in the permeability of the bladder to the diffusion of labeled water. This evidence indicates that even water is subject to some retardation by the dense diffusion barrier. Subsequent addition of vasopressin produced a further increase averaging some $50 \%$, a value in fair agreement with the previously reported figure of $70 \%(20)$. The moderate increase in diffusion permeability to water following vasopressin is consistent with the large bulk transfers of water that may be induced according to the pore hypothesis of the action of the hormone (1).

It had been observed that the permeability of the bladder to a group of small uncharged amides, typified by urea, was strikingly increased by vasopressin $(4,5)$. Studies of the labeling of the tissue with urea- $\mathrm{C}^{14}$ added to the mucosal medium indicated that the effect of vasopressin in augmenting the permeability of the bladder to urea resulted from a change in some barrier located in or near the mucosal surface of the bladder. The demonstration of solvent drag on urea had led us tentatively to assign a common site in the porous barrier for the hormonal action with respect to the penetration of the tissue by both urea and water. The present studies, however, clearly indicate that the action of vasopressin must be to increase the permeability of the dense diffusion barrier to urea. Thus either vasopressin or ampho- tericin $\mathrm{B}$ increases the permeability of the tissue to urea, and subsequent addition of the other compound elicits no further increase in permeability. This indicates that the two agents affect the same sites. Furthermore, the effect of amphotericin B on the permeability to urea occurs without an increase in net water transfer, indicating that the total effect on urea can be dissociated from any action of vasopressin on the porous barrier.

As demonstrated, amphotericin $\mathrm{B}$ produces a striking stimulation of sodium transport. Sodium transport in the toad bladder is an active process that is considered to occur by passive movement of sodium from the mucosal medium into the cells down a favorable chemical gradient with the subsequent active extrusion through the serosal surface of the epithelial cells $(9,25,26)$. It had been shown that the action of vasopressin was to increase the entry of sodium through the mucosal surface of the epithelial cells (9); the resultant increase in intracellular sodium secondarily stimulated its active extrusion across the serosal surface. After amphotericin B, vasopressin exerts no further stimulation of sodium transport. This suggests that the amphotericin B, like vasopressin, increases the entry of sodium through the mucosal surface. But, in contrast to vasopressin, amphotericin $\mathrm{B}$ does not affect the porous barrier. This

${ }^{7}$ Since a solvent drag effect has been obscrved on urea transport after vasopressin (4) and presumably must involve urea moving through the porous barrier, one might have anticipated an effect of vasopressin on the transport of urea after amphotericin B. An effect of solvent drag on urea, however, would be small with the osmotic flows observed at these small gradients (mucosal Ringer's solution diluted only 1 to 1 ) and would not be discernible from a measure of a unidirectional flux. Furthermore, only a small change in permeability, even to tritiated water, is considered to occur within the porous barrier in response to vasopressin. An increase in porosity rather than an increase in effective area for diffusion is the hormonal response characteristic of this barrier $(1,20)$. Finally, when diffusion is limited by two barriers it is the relative permeability of each that determines quantitatively the response to a change in permeability in either barrier (24). Thus it can be calculated that if the dense diffusion barrier normally provides the major resistance to the diffusion of urea in the absence of vasopressin, and if even in the presence of the hormone it still constitutes the major resistance to the diffusion of urea, any action of the hormone on the second or porous barrier would have little or no discernible effect on the diffusion of urea across both barriers. 
establishes that the dense diffusion barrier is ratelimiting for sodium and must, therefore, be the site at which vasopressin exerts its effect. Because net sodium transport is an active process, the interpretation of these results is subject to certain restrictions that were not imposed on the findings with the substances previously discussed, which move passively across the tissue. Thus the limit to the increase of short circuit current after amphotericin $\mathrm{B}$ and vasopressin may be dictated by the capacity of the pump and, therefore, not indicate the true extent to which these agents have affected the mucosal permeability.

Also vasopressin and amphotericin $\mathrm{B}$, although both affecting the same dense diffusion barrier, need not necesarily affect the same sites in this barrier. If an increase in sodium entry through the mucosal surface in response to amphotericin B saturates the active transport system, no further response would be observed to an additional entry of sodium that vasopressin might induce. Thus with sodium, amphotericin B affects more sites in the dense diffusion barrier than does vasopressin and the sites need not be the same; but with urea both compounds affect the same sites in this barrier.

To support the assumption that sodium is in fact moving through the usual active transport channels after amphotericin B rather than through some passive leaks, the effect of amphotericin B on the oxygen consumption of the tissue in the presence and absence of sodium was determined. Amphotericin B caused a large increase in oxygen consumption in the presence of sodium consistent with stimulation of active sodium transport. When all the sodium in the medium was replaced by choline or magnesium, a definite decrease in oxygen consumption was observed, consistent with the absence of sodium transport, and addition of amphotericin B in this situation failed to increase oxygen consumption. Thus the metabolic effects of amphotericin B, like vasopressin, are secondary to its action on sodium transport rather than directly on the metabolism of the tissue.

The observation has been made that lowering of the mucosal $\mathrm{pH}$ is associated with stimulation of sodium transport (21). Since this effect occurs without any detectable change in intracellular $\mathrm{pH}$, it has been interpreted as a consequence of an effect of $\mathrm{pH}$ upon the mucosal surface. In the pres- ence of amphotericin B, with the selective diffusion barrier functionally removed, acidification of the mucosal medium failed to stimulate sodium transport. This localizes the site of the hydrogen ion effect on sodium transport to the dense diffusion barrier. This interpretation is strengthened by the fact that addition of hydrogen ions to the mucosal medium actually inhibited sodium transport, an effect to be expected if destruction of the diffusion barrier allowed easy access of hydrogen ions into the cell. A similar drop in sodium transport has been found to occur when the $\mathrm{pH}$ of the serosal medium is reduced.

The removal of potassium from the serosal bathing medium has been observed to reduce or abolish sodium transport. This finding has been used as an argument to support a coupled sodium for potassium exchange as the mechanism of active sodium transport. However, in the toad bladder it was found that the major effect of removing potassium from the serosal medium was to reduce markedly the permeability of the mucosal surface to sodium (22). With little or no sodium entering the cells from the mucosal medium, none was available for active extrusion at the serosal side, and thus active sodium transport stopped. When sodium in the serosal medium was replaced by choline, the mucosal surface retained most of its permeability in the absence of serosal potassium, and under these conditions active sodium transport has been demonstrated (27). Since amphotericin B functionally removes the selective barrier at the mucosal surface, it should afford an independent method of testing the means by which the removal of potassium stops sodium transport. The prompt large increase in sodium transport in the absence of potassium upon addition of amphotericin B supports the hypothesis that the major effect of removing potassium had been on the permeability of the mucosal surface. However, when potassium was subsequently returned to the serosal medium, there occurred a further increase in short circuit current indicating that potassium played some other role in sodium transport in addition to its effect on the permeability of the mucosal barrier.

The fact that amphotericin B affects the diffusion barrier suggests that chemically this barrier is lipid-like in structure. Previous studies, in microbiological systems, have shown that amphotericin $B$ reacts with lipids, particularly sterols. It is 


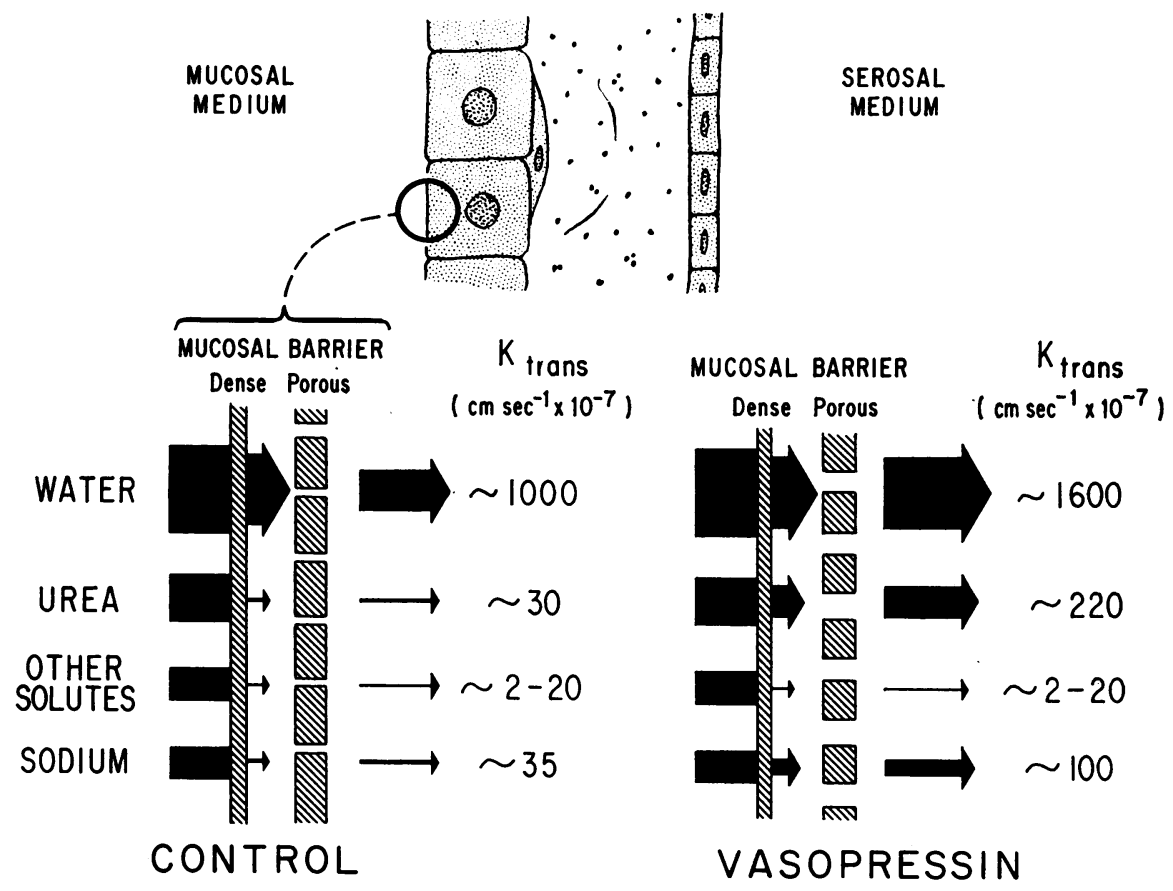

Fig. 7. Schematic Representation of the mucosal permeability Barrier. The urinary surface of the mucosal cells is represented as a dual barrier, a dense diffusion and a porous barrier, in series. All substances including water are retarded at the diffusion barrier. Vasopressin enhances the permeability of this tissue to urea and sodium by an effect on the dense diffusion barrier and to water by an effect on the porous barrier.

thought that amphotericin B exerts its toxic effect on susceptible organisms by combining with sterols in the cell membranes and thereby causing damage to the cell $(13,14)$. For this reason it is effective against fungi and protozoa $(14,28,29)$, which contain sterols in their cell membranes, but is ineffective against bacteria (14), which have little or no sterols in their cells (30). With mammalian erythrocytes in vitro amphotericin B may induce large potassium losses and hemolysis $(31,32)$. Clinically it frequently causes a marked nephrotoxicity (33). One might speculate that a similar drug-sterol interaction is responsible for these effects.

In conclusion these studies with amphotericin B allow a qualitative description of the contribution of these two diffusion barriers to the over-all permeability of this tissue and furthermore permit us to ascribe the major effects of vasopressin to the individual barriers. This is illustrated schematically by Figure 7 in which the effects of vasopressin are indicated. For water the porous barrier is the major obstacle to diffusion, and vasopressin increases the diffusion permeability by 60 to $70 \%$. The change in the porous barrier furthermore permits net movement of water by bulk flow, as previously discussed $(1,2)$. Urea is limited by the dense diffusion barrier both in the presence and absence of vasopressin, and the hormonal effect is mediated at this barrier. Sodium, like urea, is hindered at the dense diffusion barrier, and vasopressin accelerates its movement across this barrier. Most small solutes are markedly hindered at the dense diffusion barrier, and vasopressin has no discernible effect on their penetration. According to this formulation vasopressin is seen to have a dual site of action: on the porous barrier with respect to water and on the dense diffusion barrier for sodium and urea. These two barriers in or near the mucosal surface of the epithelial layer of cells determine the permeability for water, urea, and small solutes, but in the special case of sodium, the active transport process located at the serosal surface of the epithelial layer of cells 
must also be taken into account with respect to its transepithelial transport.

\section{Summary}

1) Amphotericin B, a polyene antibiotic, has been shown to stimulate sodium transport in the toad bladder. This effect, similar to that of vasopressin, results from an increase in permeability of the mucosal surface to sodium.

2) The permeability of the bladder to small solutes, e.g., potassium, chloride, and thiourea, which normally penetrate the tissue at low rates unaffected by vasopressin, was greatly increased by amphotericin B.

3) The rate of penetration of the bladder by urea was enhanced by amphotericin B or by vasopressin to a similar extent, but the subsequent addition of the second agent failed to increase the response beyond that produced by the first.

4) In contrast to the effects on the permeability of the bladder to solutes, amphotericin B had little effect on the net transport of water across the bladder, which was still dependent for its occurrence on the presence of vasopressin.

5) The findings provide independent evidence to support the hypothesis that the major resistance to penetration of this tissue resides in a double series barrier, a dense diffusion, and a porous barrier, located in or near the mucosal surface. The dense diffusion barrier is affected by either amphotericin $\mathrm{B}$ or vasopressin to allow penetration by sodium or urea; the porous barrier is acted upon by vasopressin alone to induce bulk flow of water.

6) Although acidification of the mucosal medium specifically stimulates sodium transport in this tissue, in the presence of amphotericin B acidification fails to enhance and, in fact, depresses sodium transport. This localizes the site of the hydrogen ion effect to the dense diffusion barrier.

7) The fall in sodium transport in the absence of serosal potassium is promptly reversed by amphotericin B. This confirms the hypothesis that the major effect of potassium removal on sodium transport results from obstruction to the entry of sodium into the cells.

8) All the effects with amphotericin B were elicited with the compound added to the mucosal bathing medium; no effects were detectable from the serosal side in the concentrations used.

\section{References}

1. Koefoed-Johnsen, V., and H. H. Ussing. The contributions of diffusion and flow to the passage of $\mathrm{D}_{2} \mathrm{O}$ through living membranes. Effect of neurohypophyseal hormone on isolated anuran skin. Acta physiol. scand. 1953, 28, 60.

2. Hays, R. M., and A. Leaf. The state of water in the isolated toad bladder in the presence and absence of vasopressin. J. gen. Physiol. 1962, 45, 933.

3. Andersen, B., and H. H. Ussing. Solvent drag on non-electrolytes during osmotic flow through isolated toad skin and its response to antidiuretic hormone. Acta physiol. scand. 1957, 39, 228.

4. Leaf, A., and R. M. Hays. Permeability of the isolated toad bladder to solutes and its modification by vasopressin. J. gen. Physiol. 1962, 45, 921.

5. Maffy, R. H., R. M. Hays, E. Lamdin, and A. Leaf. The effect of neurohypophyseal hormones on the permeability of the toad bladder to urea. J. clin. Invest. 1960, 39, 630.

6. Ussing, H. H., and K. Zerahn. Active transport of sodium as the source of electric current in the short circuited isolated frog skin. Acta physiol. scand. 1951, 23, 110.

7. Leaf, A., and E. F. Dempsey. Some effects of mammalian neurohypophyseal hormones on metabolism and active transport of sodium by the isolated toad bladder. J. biol. Chem. 1960, 235, 2160.

8. Hays, R. M., and A. Leaf. The problem of clinical vasopressin resistance: in vitro studies. Ann. intern. Med. 1961, 54, 700.

9. Frazier, H. S., E. F. Dempsey, and A. Leaf. Movement of sodium across the mucosal surface of the isolated toad bladder and its modification by vasopressin. J. gen. Physiol. 1962, 45, 529.

10. Frazier, H. S. Specificity of sodium transport and the biologically active form of sodium ion (abstract). J. clin. Invest. 1964, 43, 1265.

11. Petersen, M. J., and I. S. Edelman. Calcium inhibition of the action of vasopressin on the urinary bladder of the toad. J. clin. Invest. 1964, 43, 583.

12. Morel, F. Action of the neurohypophyseal hormones on the active transport of sodium in Water and Electrolyte Metabolism, J. de Graeff and B. Leijnse, Eds. Amsterdam, Elsevier, 1964, vol. 2, p. 91.

13. Lampen, J. O., P. M. Arnow, and R. S. Safferman. Mechanism of protection by sterols against polyene antibiotics. J. Bact. 1960, 80, 200.

14. Lampen, J. O., P. M. Arnow, Z. Borowska, and A. I. Laskin. Location and role of sterol at nystatinbinding sites. J. Bact. 1962, 84, 1152.

15. Sharp, G. W. G., and A. Leaf. Biological action of aldosterone in vitro. Nature (Lond.) 1964, 202, 1185.

16. Menninger, J. R., F. M. Snell, and R. A. Spangler. Voltage clamp for biological investigations. Rev. sci. Instr. 1960, 31, 519.

17. Edelman, I. S., M. J. Petersen, and P. F. Gulyassy. 
Kinetic analysis of the antidiuretic action of vasopressin and adenosine- $3^{\prime}-5^{\prime}$-monophosphate. J. clin. Invest. 1964, 43, 2185.

18. Langham, W. H., W. J. Eversole, F. N. Hayes, and T. T. Trujillo. Assay of tritium activity in body fluids with use of a liquid scintillation system. J. Lab. clin. Med. 1956, 47, 819.

19. Umbreit, W. W., R. H. Burris, and J. F. Stauffer. Manometric Techniques. Minneapolis, Burgess, 1957.

20. Hays, R. M., and A. Leaf. Studies on the movement of water through the isolated toad bladder and its modification by vasopressin. J. gen. Physiol. 1962, 45, 905.

21. Leaf, A., A. Keller, and E. F. Dempsey. Stimulation of sodium transport in toad bladder by acidification of mucosal medium. Amer. J. Physiol. 1964, 207, 547.

22. Essig, A., and A. Leaf. The role of potassium in active transport of sodium by the toad bladder. J. gen. Physiol. 1963, 46, 505.

23. Leaf, A., L. B. Page, and J. Anderson. Respiration and active sodium transport of isolated toad bladder. J. biol. Chem. 1959, 234, 1625.

24. Leaf, A. The mechanism of the asymmetrical distribution of endogenous lactate about the isolated toad bladder. J. cell. comp. Physiol. 1959, 54, 103.

25. Koefoed-Johnsen, V., and H. H. Ussing. The nature of the frog skin potential. Acta physiol. scand. 1958, 42, 298.
26. Frazier, H. S., and A. Leaf. Electrical characteristics of active sodium transport in the toad bladder. J. gen. Physiol. 1963, 46, 491.

27. Essig, A. Active sodium transport in the toad bladder despite removal of serosal potassium. Amer. J. Physiol. 1965, 208, 401.

28. Ghosh, B. K., and A. N. Chatterjee. Action of an antifungal antibiotic nystatin on the protozoa Leishmania donovani. Part III: Studies on the lysis of the cells of $L$. donovani. Ann. Biochem. 1963, 23, 173.

29. Ghosh, A., and J. J. Ghosh. Changes in the intracellular constituents of Candida albicans on nystatin and amphotericin B treatment. Ann. Biochem. 1963, 23, 113.

30. Fiertel, A., and H. P. Klein. On sterols in bacteria. J. Bact. 1959, 78, 738.

31. Kinsky, S. C., J. Avruch, M. Permutt, H. B. Rogers, and A. A. Schonder. The lytic effect of polyene antifungal antibiotics on mammalian erythrocytes. Biochem. biophys. Res. Commun. 1962, 9, 503.

32. Butler, W. T., D. W. Alling, and E. Cotlove. Potassium loss from human erythrocytes exposed to amphotericin B. Proc. Soc. exp. Biol. (N. Y.) 1965, 118, 297.

33. Butler, W. T., J. E. Bennett, D. W. Alling, P. T. Wertlake, J. P. Utz, and G. J. Hill II. Nephrotoxicity of amphotericin B. Early and late effects in 81 patients. Ann. intern. Med. 1964, 61, 175. 